\title{
Maternal transmission of translocation 2;21 associated with Down's syndrome
}

\author{
Saroj V Kotwaliwale, Vidya V Dicholkar, N D Motashaw
}

\begin{abstract}
An unusual 2;21 translocation associated with Down's syndrome is reported. The proband was a 3 year old boy, clinically diagnosed as having Down's syndrome and with a family history of Down's syndrome. Maternal age at the time of study was 28 years. Out of the four sibs with Down's syndrome three had died. Two pregnancies ended in first trimester miscarriage. The proband was found to have trisomy 21 associated with a 2;21 translocation inherited from his mother.
\end{abstract}

Down's syndrome was first described by Langdon Down in $1886^{1}$ and was subsequently confirmed to be associated with an extra chromosome 21 by Lejeune $e t$ $a l^{2}$ in 1959. The syndrome can be diagnosed at birth or shortly thereafter by the typical clinical features. The chromosome complement can be either frank trisomy 21 , mosaicism, or trisomy owing to a $D ; G$ $(13-15 ; 21)$ or $\mathrm{G} ; \mathrm{G}(21 ; 21)$ translocation. In addition, other translocations can be present. A case with an apparent translocation 21;1 associated with Down's syndrome was described by Kontras et $a l^{3}$ in 1966. We report a case of $2 ; 21$ translocation associated with Down's syndrome.

\section{Case report}

The proband, a 3 year old boy, was referred to the laboratory for cytogenetic analysis along with his parents. He was born at $81 \frac{1}{2}$ months' gestation by normal vaginal delivery. Maternal age at the time of his birth was 25 years. The child had delayed developmental milestones and had frequent respiratory problems. Clinical features included a flat occiput, epicanthic folds, depressed nasal bridge, and a protruding tongue. The hands were short and broad

Genetic Diagnostic Centre, 203 Bombay Air Conditioned Market, Tardeo Road, Bombay 400 034, India. S V Kotwaliwale, V V Dicholkar, N D Motashaw Correspondence to Dr Kotwaliwale.

Received for publication 14 May 1990.

Revised version accepted for publication 4 October 1990. with a simian crease. No cardiac anomaly was present. He was the fourth child of the family (fig 1). The first child was female and died at 1 year of age. The second and third were twin females. All of them had clinical features of Down's syndrome. However, cytogenetic analysis was not performed on them. These births were followed by two first trimester miscarriages in the mother. The father of the proband was an only child. The mother was the third in her sibship. No other family members had an abnormal child. It was not possible to question the relatives since they were out station patients.

CHROMOSOME STUDIES

Whole blood from the patient and his mother and father was cultured for 72 hours. Chromosomes were

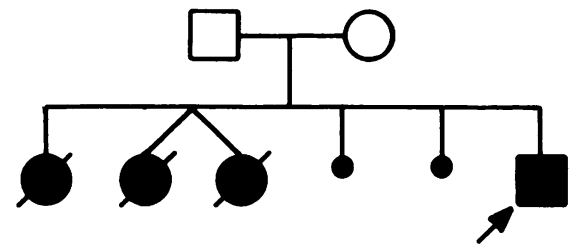

Figure 1 Pedigree of a child with Down's syndrome whose mother is a 2;21 translocation carrier.
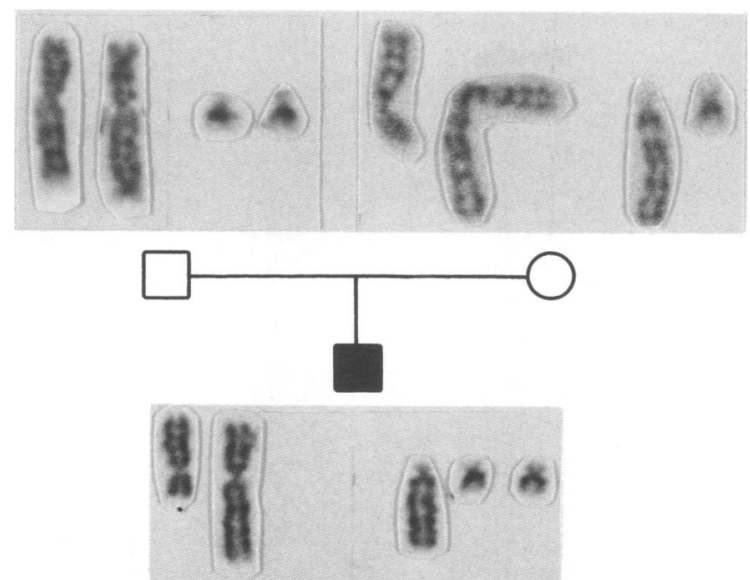

Figure 2 Chromosomes 2 and 21 in the mother and the proband. The abnormal chromosome is on the left. 
G banded using the method described by Rooney and Czepulkowskil. ${ }^{4} \mathrm{~A}$ total of 50 metaphases out of 500 metaphases obtained were studied in each case. Chromosomal analysis of the child indicated trisomy 21 associated with a $2 ; 21$ translocation $(47, \mathrm{XY},+21$, $\mathrm{t}(2 ; 21)(\mathrm{q} 21 ; \mathrm{q} 22.3) \mathrm{mat})$ (fig 2). Chromosome analysis of the mother indicated a 46,XX chromosome complement with a balanced translocation between chromosomes 2 and $21(46, \mathrm{XX}, \mathrm{t}(2 ; 21)(\mathrm{q} 21 ; \mathrm{q} 22.3))$ present in all metaphases (fig 2). The father had a normal $46, \mathrm{XY}$ karyotype.

\section{Discussion}

The clinical features and cytogenetic analysis of the proband clearly indicated that the child had Down's syndrome. The chromosome 21 together with translocation chromosome 2 at first appeared to be a large acrocentric chromosome. However, the banding pattern clearly indicated a $2 ; 21$ translocation. The mother of the proband also had this translocation and 3:1 segregation gave rise to the proband. Chromosomal analysis of the dead sibs was not performed and, although all of them were abnormal, it cannot be said with certainty that these children had Down's syndrome. This was the only family, out of 105 cases of Down's syndrome studied in this laboratory during the last two years, in which Down's syndrome resulting from a 2;21 translocation was found.

1 Down JLH. Observation on an ethnic classification of idiots. Clinical Lecture Reports, London Hospital 1886;3:259.

2 Lejeune J, Gautier M, Tarpin R. Etude des chromosomes somatiques de neuf enfants mongoliens. CR Acad Sci Paris 1959;248:1721-2.

3 Kontras SB, Carrier GJ, Cooper RF, Ambuel JP. Maternal translocation of 21/1 translocation associated with Down's syndrome. F Pediatr 1966;69:635-9.

4 Rooney DE, Czepulkowskil BH. Human cytogenetics. Oxford: IRL Press, 1986. 